\title{
Inhibition of apoptosis can be accompanied by increased Bim levels in T lymphocytes and neutrophil granulocytes
}

\author{
Cell Death and Differentiation (2007) 14, 1714-1716; doi:10.1038/sj.cdd.4402185; published online 22 June 2007
}

\author{
Dear Editor,
}

The most important regulators of cytochrome $c$ release are members from the three subgroups of $\mathrm{Bcl}-2$ family proteins. One group consists of the two proapoptotic proteins Bax and Bak, the most downstream effectors of cytochrome $c$ release that have been identified. The second group contains antiapoptotic proteins, such as Bcl-2 itself or Bcl- $\mathrm{X}_{\mathrm{L}}$ and $\mathrm{Mcl}-1$, which act to prevent the activation of Bax/Bak. The third group, known as $\mathrm{BH} 3-$ only proteins, consists of at least eight proteins that share only the short $\mathrm{BH} 3$ domain. An apoptotic stimulus activates one or several BH3-only proteins, which then cause the activation of Bax and/or Bak, possibly by binding to and relieving the inhibitory function of antiapoptotic group members. ${ }^{1,2}$

The seemingly most important $\mathrm{BH} 3-$ only protein in cells of the immune system is Bim/Bod. Analysis of Bim-deficient mice shows that Bim is important for determining the lifespan of myeloid and lymphoid cells, as these cells are increased in numbers in mice lacking $\mathrm{Bim} .{ }^{3} \mathrm{Bim}$ is also required for further homeostatic regulation in situations such as the proper termination of an adaptive immune response ${ }^{4}$ and the implementation of spontaneous apoptosis in neutrophil granulocytes. $^{5}$

How Bim is activated is not entirely clear. Although experimental overexpression of Bim kills cells, ${ }^{6}$ healthy cells can express easily detectable levels of Bim protein. An early report provided evidence that $\mathrm{Bim}$ is, in the absence of apoptosis, bound to the microtubule cytoskeleton, where it remains inactive until released. Upon its release, Bim was shown to translocate to mitochondria, to bind to $\mathrm{Bcl}-2$ and to cause apoptosis. ${ }^{7}$ However, later reports showed that $\mathrm{Bim}$ is subject to considerable transcriptional regulation. Various stimuli can cause the upregulation of Bim. Bim can further be phosphorylated on a number of sites, ${ }^{8}$ which probably regulates Bim protein abundance. Bim protein levels can also be regulated through ubiquitylation, ${ }^{9}$ suggesting that the level of Bim protein is a determinant of apoptosis induction.

However, there is evidence that Bim can, in some experimental situations, be upregulated without directly inducing apoptosis. One example is found in thymocytes: thymocytes from Bim-deficient mice have a defect in negative selection and are more resistant to $\mathrm{T}$-cell receptor signals than wild-type mice. ${ }^{10}$ In these cells, both phorbol-12-myristate13-acetate (PMA) and ionomycin induce the upregulation of Bim protein; ${ }^{11}$ however, the cells are resistant only to ionomycin- but not to PMA-induced apoptosis. ${ }^{3}$
There is at present no known reliable assay of Bim activation. Although the release from the microtubule cytoskeleton may be a measure of Bim activity, ${ }^{7}$ activation of Bim may be regulated in a different way, for instance in primary mouse T cells, where Bim has been described to be on the mitochondria already in its presumably inactive state. ${ }^{12}$ In the absence of a reliable assay to monitor Bim activity, it is tempting to equate induction of Bim expression with apoptosis induction through Bim.

In this study, we analyze two situations of apoptosis in the immune system, in which Bim plays a role, and correlate Bim expression with apoptosis. In both neutrophil granulocytes and activated T cells, Bim-dependent apoptosis occurs, but this apoptosis is reduced in experimental conditions that increase rather than decrease the expression of Bim.

Neutrophil granulocytes are constantly produced in the bone marrow and exported into the peripheral blood, where they die rapidly. ${ }^{13}$ Granulocyte counts in the peripheral blood of Bim-deficient mice are increased by a factor of about $2.5,{ }^{3}$ suggesting that the lifespan and apoptosis of granulocytes are regulated, at least in part, by Bim. Survival of granulocytes sorted from mouse bone marrow in vitro was increased in cells from $\mathrm{bim}^{-1-}$ mice (Figure 1a, reproducing earlier results ${ }^{14}$ ), indicating a role of Bim in this form of apoptosis.

In macrophages and dendritic cells (DC), toll-like receptor (TLR) stimuli such as lipopolysaccharide (LPS), increase the levels of Bim. ${ }^{15}$ Neutrophils also respond to TLR-signals and it is known that human neutrophils can be kept alive by LPS in cell culture. ${ }^{16}$ As shown in Figure $1 \mathrm{a}$, this was also found to be the case for neutrophils sorted from mouse bone marrow: LPS stimulation reduced spontaneous apoptosis. At the same time, LPS caused a very clear upregulation of Bim levels in the cells (Figure 1b). The levels of Bim are thus inversely correlated with the propensity to undergo apoptosis.

Bim activity could be countered by increased expression levels of antiapoptotic proteins, such as Bcl-2, Bcl- $\mathrm{X}_{\mathrm{L}}$ and $\mathrm{Mcl}-1$. Indeed, there was a concomitant induction of $\mathrm{Mcl}-1$ and $\mathrm{A} 1$ protein, while no change in the levels of $\mathrm{Bcl}-2$ or $\mathrm{Bcl}-\mathrm{X}_{\mathrm{L}}$ was observed (Figure 1b). It is therefore possible that the Bim upregulation in neutrophils is only tolerated because of the concomitant upregulation of $\mathrm{Mcl}-1$. However, there is the very clear constellation of the increase in Bim levels that is accompanied by the decrease rather than increase in a form of cell death that is at least in part caused by Bim.

In activated T cells responding to growth factor withdrawal with apoptosis, a transcriptional axis was recently described: 
a

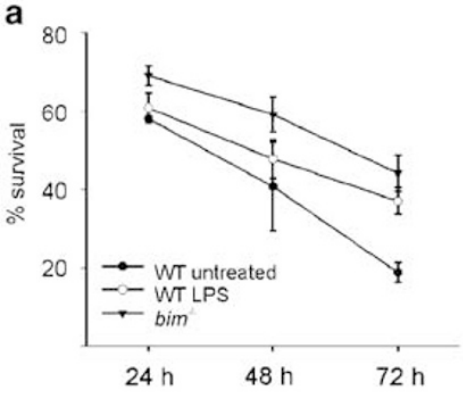

b
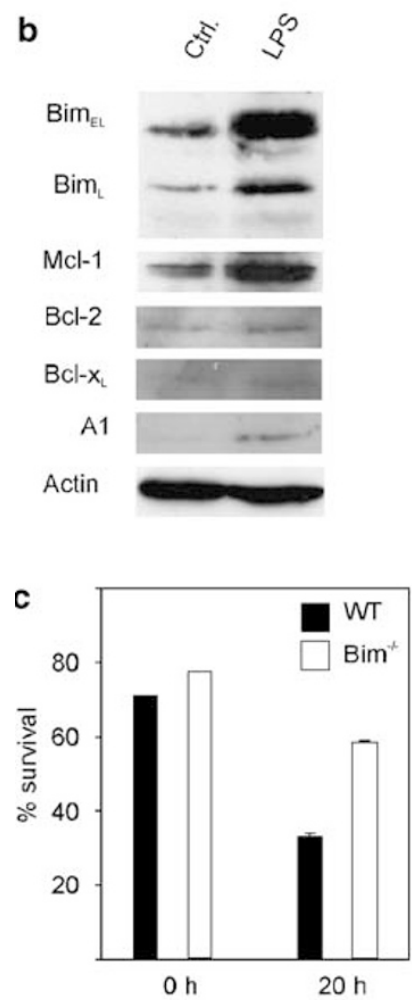

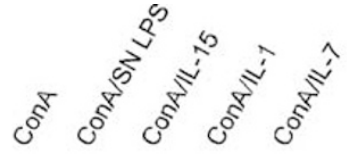

Exp. 1

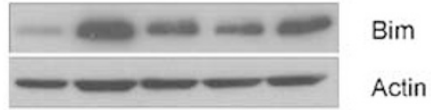

$\% \mathrm{~T}$ cells alive:

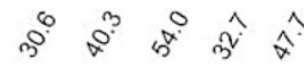

Exp. 2

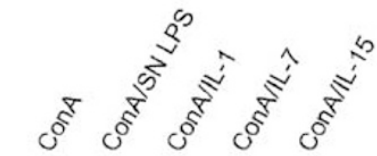

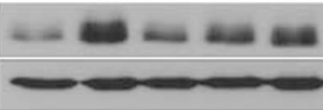

Bim

Actin

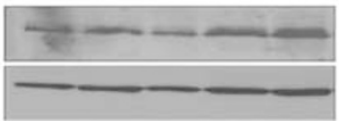

Bcl-x

Tubulin

$\% \mathrm{~T}$ cells alive:
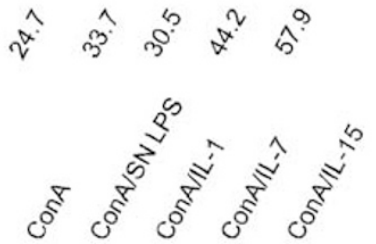

Exp. 3

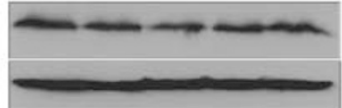

Bax

Actin
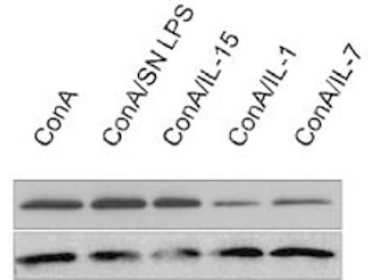

$\mathrm{BCl}-2$

Actin

$\mathrm{MCl}-1$

Actin

Figure 1 (a) Survival of neutrophils isolated from mouse bone marrow. Bone marrow granulocytes from WT or bim ${ }^{-l-}$ mice $\left(5 \times 10^{5} /\right.$ well in a $12-$ well plate) were incubated without further stimulation in complete medium for the indicated time periods. To aliquot cultures of WT cells, LPS was added (1 $\mu \mathrm{g} / \mathrm{ml})$. Survival rate was assessed by propidium iodide staining for loss of membrane integrity followed by flow cytometry analysis. Shown are the mean values/S.E.M. of three independent experiments (two experiments with one mouse per genotype, one with two WT mice). (b) Expression of Bim and Bcl-2 family members in neutrophils stimulated with LPS. Bone marrow granulocytes from WT mice $\left(1 \times 10^{6} /\right.$ well in a 12-well plate) were either stimulated with LPS $(1 \mu \mathrm{g} / \mathrm{ml})$ or left untreated for $24 \mathrm{~h}$. Whole-cell lysates were prepared in Laemmli buffer and expression of Bim and the indicated Bcl-2 family proteins was analyzed by Western blotting. Actin served as a loading control. (c) Enhanced survival of activated T cells from $\mathrm{bim}^{-1-}$ mice. Spleen cells from WT or bim ${ }^{-1-}$ mice were stimulated with ConA in vitro for 3 days. T cells were then purified, washed and transferred to 96-well plates. Survival of $\mathrm{CD}^{+}$cells was measured at the indicated time points by flow cytometric analysis. Very similar survival differences were seen in three more independent experiments with slightly different conditions; a more extensive time course has been published. ${ }^{18}$ (d) In activated T cells, Bim is upregulated in the presence of interleukin (IL)-1, IL-7 or IL-15. Purified T cells were stimulated with ConA, either alone or in the presence of supernatant derived from LPS-stimulated mouse bone marrow-derived dendritic cells or the recombinant cytokines IL-1, IL-7 or IL-15. On day 3, samples were analyzed for the expression of Bim, $\mathrm{Bcl}-\mathrm{x}_{\mathrm{L}}, \mathrm{Mcl}-1, \mathrm{Bcl}-2$ or Bax. Similar Bim upregulation was observed in 10 experiments; the other blots are representative of four (Bax, Mcl-1), three (Bcl-2) or six (Bcl- $\mathrm{x}_{\mathrm{L}}$ ) experiments. Survival of T cells is shown for two experiments (percentages are mean of triplicates where cells upon stimulation were placed in culture in complete medium; survival was tested $20 \mathrm{~h}$ later). For experimental details, see Supplementary information 
loss of signal through interleukin (IL)-2 receptor leads to the deactivation of AKT and the activation of FOXO3a, which then causes the transcriptional induction of both Bim and Puma. ${ }^{17}$ This prompted us to check the levels of Bim in a similar situation that we have described recently. Unlike IL-2, whose continued presence seems to be required to convey survival, a number of cytokines were found to confer a 'priming effect' on activated $T$ cells, that is, their addition during mitogen stimulation leads to improved T-cell survival even after the cytokine has been taken away. This effect can be seen with the cytokines IL-1, IL-7 and IL-15, as well as with a supernatant from LPS-stimulated DC. ${ }^{18}$ The form of apoptosis, thus prevented by these cytokines, is at least in part implemented by Bim (Figure 1c). ${ }^{17,18}$ It could therefore be expected that the priming by these cytokines causes the downregulation of Bim. However, the contrary was the case. All of the cytokines that primed for survival caused the clear upregulation of Bim (Figure 1d). In this case, the levels of $\mathrm{Bcl}-2$, Bcl- $\mathrm{X}_{\mathrm{L}}, \mathrm{Mcl}-1$, Bax and Bak remained constant with perhaps some minor inconsistent changes (Figure 1d). These data therefore describe another situation where the upregulation of Bim is accompanied by a reduction of Bim-dependent apoptosis. In a minority of experiments, a shift of a portion of Bim protein was observed that is probably indicative of Bim phosphorylation (one such experiment is shown in Figure 1d, experiment 2), which has been hypothesized to be associated with protection from apoptosis, ${ }^{19}$ perhaps through enhanced proteasomal degradation. ${ }^{20}$ However, since the levels of Bim increased, this is inconsistent with enhanced degradation. Further, the shift was seen only in about $20 \%$ of experiments and it is unclear whether cytokine addition changed the ratio of phosphorylated to unphosphorylated Bim (Figure 1d). It therefore appears unlikely that phosphorylation plays a major role in this situation.

It is not clear why the amount of Bim that is added by cytokine priming is not active. It is possible that either a surplus of antiapoptotic proteins is sufficient to bind and neutralize Bim or that Bim is kept inactive by other mechanisms such as sequestration to microtubules. Whatever the mechanism, there seems to be the distinct possibility that a substantial upregulation of Bim can occur in the absence of apoptosis induction.

These data describe the inverse correlation of Bim levels with apoptosis in two cell types. Our knowledge of the respective roles of $\mathrm{BH} 3-$ only proteins in apoptosis is rapidly expanding and advances are being made in the understanding of their regulation. The abundance of Bim appears to be finely tuned both by changes in transcription in response to environmental signals and by the regulation of its degradation through the proteasome, by virtue of its phosphorylation and ubiquitylation. These level changes may play major roles in Bim activation and it is possible that different populations of Bim molecules exist that are active or not. However, a simple analysis of Bim levels can be misleading and it may be not out of place to caution against accepting an increase of Bim levels as a bona fide indicator of Bim-dependent apoptosis.

Acknowledgements. We are grateful to Ms. Stephanie Potthoff and Ms. Anna Buchala for the help with experiments.

\author{
A Bauer ${ }^{1,2}$, S Kirschnek ${ }^{1,2}$ and G Häcker ${ }^{\star, 1}$ \\ 1 Institute for Medical Microbiology, Immunology and Hygiene, Technische \\ Universität München, Munich, Germany \\ 2 These authors contributed equally to this work \\ * Corresponding author: G Häcker, Institut for Medical Microbiology, Trogerstr. \\ 30, Munich D-81675, Germany. Tel: + 49894140 4134; \\ Fax: + 49894140 4868; E-mail: hacker@|rz.tum.de
}

1. Adams JM, Cory S. Trends Biochem Sci 2001; 26: 61-66

2. Chen L, Willis SN, Wei A, Smith BJ, Fletcher JI, Hinds MG et al. Mol Cell 2005; 17: 393-403.

3. Bouillet P, Metcalf D, Huang DC, Tarlinton DM, Kay TW, Kontgen F et al. Science 1999; 286: $1735-1738$.

4. Hildeman DA, Zhu Y, Mitchell TC, Bouillet P, Strasser A, Kappler J et al. Immunity 2002; 16: 759-767.

5. Wong HK, Fricker M, Wyttenbach A, Villunger A, Michalak EM, Strasser A et al. Mol Cell Biol 2005; 25: 8732-8747.

6. O'Connor L, Strasser A, O'Reilly LA, Hausmann G, Adams JM, Cory S et al. EMBO J 1998; 17: 384-395.

7. Puthalakath H, Huang DC, O'Reilly LA, King SM, Strasser A. Mol Cell 1999; 3: 287-296.

8. Ley R, Ewings KE, Hadfield K, Cook SJ. Cell Death Differ 2005; 12: 1008-1014.

9. Akiyama T, Bouillet P, Miyazaki T, Kadono Y, Chikuda H, Chung UI et al. EMBO J 2003; 22: 6653-6664.

10. Bouillet P, Purton JF, Godfrey DI, Zhang LC, Coultas L, Puthalakath H et al. Nature 2002; 415: 922-926.

11. Cante-Barrett K, Gallo EM, Winslow MM, Crabtree GR. J Immunol 2006; 176: 2299-2306.

12. Zhu Y, Swanson BJ, Wang M, Hildeman DA, Schaefer BC, Liu X et al. Proc Natl Acad Sci USA 2004; 101: 7681-7686.

13. Desaga JF, Parwaresch MR. Klin Wochenschr 1972; 50: 795-796.

14. Villunger A, Scott C, Bouillet P, Strasser A. Blood 2003; 101: 2393-2400.

15. Kirschnek S, Ying S, Fischer SF, Hacker H, Villunger A, Hochrein $\mathrm{H}$ et al. J Immunol 2005; 174: 671-679.

16. Colotta F, Re F, Polentarutti N, Sozzani S, Mantovani A. Blood 1992; 80: 2012-2020.

17. You H, Pellegrini M, Tsuchihara K, Yamamoto K, Hacker G, Erlacher M et al. J Exp Med 2006; 203: 1657-1663.

18. Bauer A, Villunger A, Labi V, Fischer SF, Strasser A, Wagner $\mathrm{H}$ et al. Proc Natl Acad Sci USA 2006; 103: 10979-10984.

19. Seward RJ, von Haller PD, Aebersold R, Huber BT. Mol Immunol 2003; 39: 983-993.

20. Ley R, Balmanno K, Hadfield K, Weston C, Cook SJ. J Biol Chem 2003; 278 $18811-18816$.

Supplementary Information accompanies the paper on Cell Death and Differentiation website (http://www.nature.com/cdd) 